УДК 811.112 .2

МРНТИ 16.21.25

DOI 10.37238/1680-0761.2021.83(3).6

\author{
${ }^{1}$ Поляничко М.В.*, ${ }^{2}$ Яковлюк А. Н. \\ ${ }^{1,2}$ Национальный государственный университет физической культуры, спорта и \\ здоровья им. П.Ф. Лесгафта, Санкт-Петербург, Россия \\ *Автор-корреспондент: marias777@ rambler.ru
}

E-mail: marias777@rambler.ru, arniluk@yandex.ru

\title{
ФОРМИРОВАНИЕ НАЦИОНАЛЬНОГО НЕМЕЦКОГО ЯЗЫКА В ПЕРИОД ХІІ - ХVIII СТОЛЕТИЙ И ЕГО ЛЕКСИЧЕСКИЕ И ГРАММАТИЧЕСКИЕ ОСОБЕННОСТИ
}

\begin{abstract}
Аннотация. Сравнительно-исторический метод исследования дает возможность показать прочесс становления современных грамматических систем, формирования словарного состава языков.

Анализ материала позволил выявить следуюшие основные особенности формирования литературного немеџкого наџионального языка в период XII - XVIII столетий:

- Происходят изменения в системах склонения и спряжения.

- Растущее использование настоящего времени (презенса) в описании прошльх событий.

- В словообразовании ранненововерхненемечкого большую роль играло словосложение.

- Многие старые лексические единицы использовались в новых значениях.

- Вследствие экономических и общественных изменений стали активно
\end{abstract} формироваться специиальные языки различных социальных групп, из которых многие слова и выражения проникли в национальный язык.

- Большое влияние оказывал латинский язык, значение других языков снизилось по сравнению с латинским.

- Наиболее значимым для развития национального немецякого языка оказался восточно-средненемецкий район Германии, в котором происходило своего рода смешение нижненемеиких, средненемецких и верхненемецких элементов.

Ключевые слова: начиональный немецкий язык, грамматическая форма, словарный состав, композитьl, словообразование.

\section{Введение}

В XII и XIII веках немецкий языковой ареал расширяется преимущественно на восток, из многих славянских деревень крестьяне были изгнаны, и немецкие крестьяне поселились на этих территориях [1].

На новообретенных территориях на севере и северо-востоке укореняется нижненемецкий вариант языка, восточные территории вовлекаются в средненемецкую языковую область, на юго-востоке господствует баварский вариант.

В этот период полного развития феодализма, периода расцвета рыцарства, на среднем и нижнем Рейне, а затем в Южной и Центральной Германии развивалась богатая культурная жизнь. Грандиозные строения и великолепные стихотворные произведения свидетельствуют 
о расцвете немецкой культуры. Следует отметить, что помимо духовенства в еще большей степени носителями этой культуры являлись представители рыцарства. Поэты рыцарской эпохи создали для себя литературный язык, который избегал диалектных форм и «невежливых» выражений. Однако несмотря на все старания созданный литературный язык не смог полностью избежать характерных особенностей разговорного языка [2].

Для словаря немецкого языка большое значение сыграла высокоразвитая французская рыцарская культура. Крестовые походы способствовали закреплению в словарном составе немецкого языка итальянских и восточных лексических единиц, а освоение славянских территорий привносило в немецкий язык славянские слова [3].

Из-за ослабления гласных звуков в безударных окончаниях в средневерхненемецком происходит сильное упрощение склонения. Разные классы склонения древневерхненемецкого уже в большинстве случаев не отличаются друг от друга:

\section{ahd.}

Sg. NA. tag
G. tages (-as)
D. tage (-a)
I. $\quad \operatorname{tagu}(-\mathrm{o})$

Pl. NA. taga (-a)
G. tago
D. tagum (-om, -un)

$\begin{array}{lll} & & \text { mhd. } \\ \text { Sg. } & \text { N. } & \text { tac } \\ & \text { G. } & \text { tages } \\ & \text { D. } & \text { tage } \\ & \text { A. } & \text { tac } \\ \text { PI. } & \text { N. } & \text { tage } \\ & \text { G. } & \text { tage } \\ & \text { D. } & \text { tagen } \\ & \text { A. } & \text { tage }\end{array}$

(ahd. - древневерхненемецкий, $\boldsymbol{m} \boldsymbol{h} \boldsymbol{d}$. - средневерхненемецкий)

Определенным упрощениям была подвергнута и система спряжения.

Затрагивая синтаксические особенности средневерхненемецкого, следует остановиться на отрицании.

Отрицание первоначально выражалось только при помощи частиц $\boldsymbol{n i}(\boldsymbol{n e})$ или $\boldsymbol{e n .}$

ahd. ih ni (ne) wei $\square==$ ich weiß nicht

Это простое отрицание усиливается путем добавления объекта ahd. niwiht, mhd. niht (nichts). Так что фраза теперь выглядит следующим образом:

mhd. ich en wei $\square$ (enwei $\square$ ) niht.

Начиная с XII века наблюдается постепенное исчезновение древней формы отрицания c ni (ne) или en; а в XV веке она уже больше не употребляется. Отрицание при глаголе выражается исключительно при помощи „nicht": ich weiß nicht.

Характеризуя состояние словарного запаса в средневерхненемецком по сравнению с древневерхненемецким, нужно подчеркнуть исчезновение из употребления (или сохранение только в составе сложных слов) многих ранее широко употреблявшихся слов [4]:

$\begin{array}{llc}\begin{array}{l}\text { ahd. } \\ \text { gomo }\end{array} & \text { (еще сохранилось в слове «Bräutigam») } \\ & \text { man } & \\ \text { diot } & (\text { сохрагнилось в «Dietrich») } & \text { volc } \\ \text { barn } & (\text { тот же корень как и в «gebären») } & \text { kint }\end{array}$

Рассматриваемый в статье период отмечен и многочисленными заимствованиями из других языков [5]:

1. Заимствованные слова из французского языка.

Влияние французского усилилось посредством разнообразных культурных и литературных взаимоотношений между Францией и Германией, особенно между французскими и немецкими рыцарями, которые тесно контактировали друг с другом во время второго крестового похода (с 1147 г. по 1149 г.). Заимствования из французского языка - это в основном слова из рыцарской жизни: 
mhd. aventiure (Abenteuer), kastël (befestigter Ort, Schloß), turnei (Turnier), lanze (Lanze), pris (Preis), panzier (Panzer), harnasch (Harnisch), fin (fein), palas (Saalbau)

Впрочем, можно привести в качестве примеров и лексические единицы из других областей деятельности:

Visier, Kumpan, Sold, Quartier, Fabel, Melodie, Flöte, Tanz, Firlefanz, Diamant, Samt, Manier, tanzen, ade (приветствие при прощзани)

Влияние французского языка было столь значительным, что оно коснулось даже словообразования. Так, было принято французское инфинитивное окончание -ier, которое стало использоваться в немецком языке в качестве -ieren для образования новых глаголов от существительных и прилагательных:

\section{buchstabieren, hausieren, stolzieren.}

Также суффикс -lei в mancherlei и allerlei происходит из французского. Окончание -ei (mhd. -ie), например, в Jägerei, Zauberei, тоже было принято из французского и соединилось с немецкими корневыми основами.

2. Заимствования из итальянского и восточных языков.

Влияние Италии в это время было незначительным, но, тем не менее, определенные единицы были взяты и из этого языка:

$\begin{array}{lll}\boldsymbol{m h d} . & \text { ital. } & \\ \text { spacziren } & \text { spaziare } & \text { (spazieren) } \\ \text { karratsch } & \text { carroccio } & \text { (Wagen) }\end{array}$

Однако итальянский язык заимствовал слова из восточных языков, некоторые из которых крестоносцы привнесли в немецкий словарный состав. Слово Joppe пришло в немецкий через итальянское слово giuppa из арабского. Слово Schach происходит из персидского, слово matt - из арабского:

\section{schah mat = der König ist tot.}

Во время крестовых походов в немецкий язык вошли также слова Kampfer, Zucker, Sirup и Giraffe. Слова Kampfer и Zucker - индийского происхождения, Sirup происходит из арабского. Giraffe восходит к арабскому zurafa.

- Заимствования из славянских языков.

Благодаря освоению восточных территорий в немецкий язык проникали славянские слова:

польск.

granica

tvarog

\section{mhd.}

grenize (Grenze)

tware, quarc (Quark)

Также славянские топонимы были приняты немецким языком:

\section{Leipzig (ср. рус. липа) \\ Rostock (ср. рус. растекаться, ток) \\ Kamenz (ср. рус. камень) \\ Lübeck (cp. pус. любить)}

3. Влияние латинского языка на немецкий язык в средневерхненемецкий период проявляется в заимствованиях из терминологии различных наук, особенно медицины, и из церковной латыни [6]. В XIII веке иностранные имена, даваемые при крещении, стали активно вытеснять древневерхненемецкие имена:

Markus, Paulus, Augustus, Antonia и др.

Рассматриваемый период характеризуется также изменениями значений внутри словарного состава.

В древневерхненемецкий период слово hel (nhd. hell) обозначало tönend (hallen), в средневерхненемецкий период слово получило значение glänzend. 
Слово edel обозначало в древневерхненемецком языке вначале только благородное происхождение. Под влиянием мистики в дальнейшем слово стало служить для обозначения характера.

Слово getregede (= Getreide) обозначало все, что можно было носить (одежду, багаж и т.п.). В течение XII и XIII веков слово стало обозначать все, что дает земля (фрукты, траву, цветы и т.п.). В XIV столетии слово получило значение, которым обладает и по сей день.

Лексическая единица hochgezit обозначала любой церковный или светский праздник. В XIII веке для обозначения подобного события получило распространение заимствованное слово Fest, а слово Hochzeit постепенно получило то значение, которое известно нам сейчас.

Под влиянием рыцарства также происходило изменение в обращении. Вплоть до XII века повсеместно служило обращение с использованием „дu". В XII веке в придворных кругах получило распространение обращение „Ihr". „Dü осталось как форма обращения среди родственников, друзей и среди низших слоев населения, например, крепостных крестьян, служанок, слуг и путешественников. Начиная с XVII века обращение „Ihr" вытесняется обращением „Sie".

Постепенно в связи с экономическим, политическим и общественным развитием в период раннего капитализма все сильнее становится потребность в едином обиходном языке общения. В ганзейской области сложился нижненемецкий, на юго-востоке - от Вены до Нюрнберга - верхненемецкий обиходный язык. Большое влияние на развитие национального немецкого языка оказал восточно-средненемецкий район Германии, в котором происходило своего рода смешение нижненемецких, средненемецких и верхненемецких элементов языка $[7,8]$.

Большое значение для образования национального языка имели изобретение книгопечатания с подвижными буквами и деятельность Лютера, благодаря которой восточно-средненемецкий вариант во многом стал основой национального языка.

Характеризуя важнейшие изменения в системе грамматических форм и синтаксисе ранненововерхненемецкого периода, необходимо в первую очередь указать на изменения в системах склонения и спряжения.

За счет редукции безударного $\boldsymbol{e}$ после суффиксов и корневых слогов в значительной степени исчезли различия, которые еще продолжали существовать в средневерхненемецком между классами склонения [9]. С этим явлением часто было связано изменение рода:

$\begin{array}{llll}\text { mhd. } & \text { diu witze } & \text { diu aventiure } & \text { diu klafter } \\ \text { nhd. } & \text { der Witz } & \text { das Abenteuer } & \text { der Klafter }\end{array}$

Форма множественного числа на -er была в средневерхненемецком только у немногих существительных среднего рода. В ранненововерхненемецком она встречается во многих существительных среднего и мужского рода:

\section{Häuser, Kinder, Länder, Wörter, Geister, Würmer.}

Умляут, который встречался изначально только во множественном числе существительных, у которых в древневерхненемецком в окончании стоял $\boldsymbol{i}$, стал теперь показателем множественного числа во многих существительных:

\section{Höfe, Vögel, Stäbe, Nägel, Häfen, Öfen.}

B XV веке множественное число в немецком стало характеризоваться использованием -s. В разговорной речи и часто даже в литературном языке соседствуют:

\section{Jungen—Jungs, Kerle—Kerls, Mädel—Mädels, Fräulein-Fräuleins.}

На обширных пространствах Южной и Центральной Германии начиная с XV столетия старый претерит почти полностью вышел из употребления. Он был заменен описательной формой: ich aß - ich habe gegessen. Если претерит оставался, то ликвидировалось вызываемое аблаутом различие в единственном и множественном числе:

$$
\begin{array}{lll}
\text { mhd. } & \text { vant - vunden } \\
\text { zoch - zugen } & \text { greif - griffen warf - wurfen }
\end{array}
$$




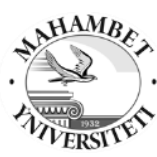

nhd. fand - fanden zog - zogen griff - griffen warf - warfen

Унификация после гласной множественного и единственного числа шла с юга немецкого языкового пространства. Лютер использовал в единственном числе еще старые формы [10].

Разница между 1 и 3 лицом множественного числа в настоящем времени (презенсе) исчезла. Форма 3 лица совпало с формой 1 лица:

$\begin{array}{llll}\text { mhd.: } & \text { 1. P. Pl. } & \text { nëmen } & \text { neren } \\ & \text { 3. P. Pl. } & \text { nëment } & \text { nerent } \\ \text { nhd.: } & \text { 1.P.Pl. } & \text { nehmen } & \text { nähren } \\ & \text { 3. P. Pl. } & \text { nehmen } & \text { nähren }\end{array}$

В качестве нововведений в синтаксисе могут рассматриваться следующие моменты: событий.

a) Растущее использование настоящего времени (презенса) в описании прошлых

б) В ранненововерхненемецком союз $\boldsymbol{o b}$ заменяется постепенно при помощи wenn; $\boldsymbol{w e n n}$ вводит теперь временные и условные предложения, $\boldsymbol{o b}$ используется преимущественно в косвенных вопросительных предложениях.

с) Использование несклоняемых форм прилагательных вместе со склоняемыми формами исчезает. Они сохранились лишь в отдельных речевых оборотах (sich lieb Kind machen), в народных песнях и в сказках („Da kam ein grau Männlein ...").

mhd.: ein guot man oder ein guoter man

nhd.: ein guter Mann

Описание изменений в словарном составе представляется целесообразным начать с новшеств в области словообразования.

В ранненововерхненемецком особенно часто появляются сложные слова, в которых первая непосредственно составляющая синтаксически зависима от второй непосредственно составляющей [11]. Такие сложные слова встречаются в следующих формах:

a) зависимый от существительного аттрибутивный генетив с существительным образует новое сложное существительное:

des Fleisches Lust - Fleischeslust (Luther), des Landes Fürst - Landesfürst, der Sonne Schein - Sonnenschein, der Frauen Zimmer - Frauenzimmer.

б) объединение прилагательного и существительного в сложном слове:

das sauer Kraut - Sauerkraut, das wild Schwein - Wildschwein, der rot Wein Rotwein, der junge Gesell — Junggeselle.

в) $\boldsymbol{s}$ в родительном падеже существительных мужского рода наблюдается также в некоторых композитах с существительными женского рода:

Hochzeitslied, Hilfsmittel, Arbeitsfreude, Freundschaftsbund.

г) В ранненововерхненемецком периоде начинают встречаться производные от группы слов, которые связаны друг с другом синтаксически:

Anteil nehmen - Anteilnahme, bekannt machen - Bekanntmachung, früh aufstehen -

Frühaufsteher, die neuen Sprachen - neusprachlich, dieses Jahr — diesjährig.

Старый словарный состав теряется с течением времени и сохраняется лишь в сложных словах:

jehen = sagen; dagen $=$ schweigen $;$ turren = wagen; schenzeln $=$ beschimpfen; mein = falsch ( сохранилось в Meineid); dëgen = Held; gedinge = Gedanke, Hoffnung; wine = Freund; lint = Schlange $($ сохранилось в Lindwurm); vridel = Geliebter; sëdel = Sessel, Sitz; dicke = oft .

Многие слова из ранненововерхненемецкого, которыми мы пользуемся и сегодня, имели в средневерхненемецком языке совсем иное значение [12]:

as (Aas)

arebeit (Arbeit)

ellende (elend)
Speise, Nahrung

Mühsal, Kampf

außer Landes, verbannt 


$\begin{array}{ll}\text { gemein (gemein) } & \text { gemeinsam, allgemein } \\ \text { gast (Gast) } & \text { Fremder } \\ \text { geheim (geheim) } & \text { zum Hause gehörig } \\ \text { grop, grob (grob) } & \text { an Masse groß, dick, stark } \\ \text { knëht (Knecht) } & \text { Knabe, Jüngling, Krieger } \\ \text { kranc (krank) } & \text { kraftlos, schwach, schlank } \\ \text { mat (matt) } & \text { nur Ausdruck im Schachspiel } \\ \text { milte (mild) } & \text { freigebig } \\ \text { ser (sehr) } & \text { wund, verwundet, leidend } \\ \text { slëht (schlecht) } & \text { schlicht } \\ \text { tugent (Tugend) } & \text { Tüchtigkeit, Kraft } \\ \text { witze (Witz) } & \text { Wissen, Verstand, Klugheit }\end{array}$

Сильная социальная передислокация и стремительное развитие новых профессий в период позднего средневековья и раннего капитализма привели к формированию выраженной специальной лексики для различных профессиональных отраслей.

Уже в древневерхненемецкое время духовенство и крестьяне выступали на языковой арене с собственным словарным запасом; в средневерхненемецкий период к этим обособленным группам прибавились рыцари. В ранненововерхненемецком периоде в результате развития городов, ремесла, горного дела и строительства возникли предпосылки для дальнейшей дифференциации лексики по отдельным профессиям и социальным группам.

В соответствии с двумя обширными торговыми зонами на немецкой территории возникает и развивается «язык торговли» в ганзейском районе на основе нижненемецкого, а в районе городов Нюрнберг, Аугсбург, Ульм и Базель - на верхненемецкой основе. Специальный словарь на нижненемецкой основе был практически утерян из-за упадка ганзейской торговли, и только некоторые выражения вошли в национальный язык:

Stapel, Fracht, Unkosten, Stockfisch, Laken, Linnen, Inlett, Römer, Packen, Stoff, Trense, Börse, Gardine.

Южно-немецкие города имели оживленные торговые связи с Северной Италией. Благодаря этому большое число итальянских слов проникало в торговый язык верхненемецкого языкового пространства:

netto, brutto, Bank, Konto, Risiko и т. д.

Расцвет ремесел приводит к тому, что многие слова, «привязанные»к той или иной гильдии, получали особые значения:

Schneider (значение сузилось до сегодняшнего), wirken (означало в mhd. любой вид деятельности; сузилось до значения «производить ткани, коврыл»), gerben (в mhd. gar обозначает вначале «заканчивать, доводить что-либо до конща»; с дополнением Fellnолучает спеииальное значение), Dach (в $\mathrm{mhd}$. еще повсеместно со значением «покрывало любого вида», сузилось и получило в языке строителей значение «крыша дома»), Zеile (означало первоначально «ряд»; писеи же понимает слово уже в значении «буквенный ряд»).

Специальная лексика охотников содержала как старый словарный состав (Wildfang, naseweis, unbändig, bärbeißig, vorlaut), так и слова из французского (pirschen, Koppel).

В лексике моряков отражается развитие мореплавания, и в их профессиональный язык входит много нижненемецких, голландских и английских слов:

Matrose, Maat, Kombüse, Boot, Flagge, Lotse, Ballast.

С возникновением наемных войск сильное развитие получил специальный язык солдат, в который активно проникали слова из французского, испанского, итальянского и славянских языков.

В ранненововерхненемецком периоде самое сильное влияние на немецкий словарный состав оказывает латинский язык. В результате экономического подъема южно-немецких, 
рейнских и северных городов с середины четырнадцатого столетия создаются многочисленные университеты как учебные заведения для богатой буржуазии, а также должностных лиц князей. Из Италии идеи гуманизма проникли в Германию, что приводило к значительному подъему искусства и наук, особенно естественных. Нужно при этом отметить, что, несмотря на большой подъем немецкой прозы в шестнадцатом веке, многочисленные научные труды этого времени были написаны тем не менее на латинском языке.

Научная деятельность, церковь и юриспруденция рассматриваемого периода времени дали нам следующие лексические единицы:

Reliquie, Prozession, Requiem, Monstranz, Text, Traktat, Glosse, Philosophie, Logik, Metaphysik, Materie, diskutieren, addieren, subtrahieren, Extrakt, Essenz, Medizin, Patient, kurieren, operieren, protestieren, Advokat, Amnestie, Prozeß, Klient, konfiszieren, adoptieren, Instanz, Kontrakt, Inserat.

Многие слова из области школьного образования особенно часто восходят к латинскому языку:

Abitur, Akademie, Auditorium, Aula, Dozent, Examen, Fakultät, Ferien, Gymnasium, Kolleg, Rektor, Professor, Semester, Student, absolvieren, diktieren, experimentieren, immatrikulieren, interpretieren, korrigieren.

Многие старые термины в музыке имеют также латинское происхождение:

Terz, Quarte, Quinte, Oktave, Dissonanz, Melodie, Note, Takt, Fuge, komponieren.

В кругах гуманистов стало даже привычкой добавлять к фамилии латинский суффикс или совсем перевести ее на латынь или греческий:

Krause - Crusius, Kurz - Curtius, Grote - Grotius, Schmied - Faber, Hirt - Pastor, Weber - Textor, Ölschläger - Olearius, Fuchs - Vulpius, Neumann - Neander, Schwarzert - Melanchthon.

Влияние латинского языка становится ощутимым и в построении предложения. Частое употребление welcher в качестве относительного местоимения, отсутствие артикля в казенном языке, конечное положение спрягаемого глагола в главном предложении и другие особенности латинского синтаксиса проникли в научные трактаты, переводы и документы.

Влияние Французского языка на словарный запас немецкого языка было в ранненововерхненемецком периоде значительно меньше, чем во время расцвета рыцарства. В XV, XVI и начале XVII века были заимствованы среди прочих слов:

Papagei, Appetit, Audienz, Konversation, Adresse, Truppe, Garde, Degen, Offizier, Leutnant, Garnison, Armee, Bombe.

Значительнее было влияние итальянского и испанского языков; оно является результатом торговых связей Верхней Германии с Италией и политических отношений Габсбургов в Испании. Также наемники привозили с собой из своих военных походов итальянские и испанские слова и выражения. Воздействие итальянского и испанского видно лучше всего в специальной лексике купцов, моряков и наемников:

Kasse, Kredit, Kapital, Bilanz, Kontor, Muster, Zitrone, Rosine, Orange, Jasmin, Tasse, Golf, Kompass, Galeere, Kapitän, Fregatte, Granate, Grenadier, Kavallerie, Infanterie, Kommando, Arsenal.

Поскольку все эти слова перекликаются в различных романских языках и имеют почти одинаковую форму, не всегда можно точно сказать, из какого языка - итальянского, испанского или французского - они пришли в немецкий. Иногда нидерландский язык играл роль посредника, как в случае со словами Rosine, Kontor, Orange.

В начале XIV века вследствие укрепления Чехии и Польши и благодаря развивающимся торговым отношениям с этими странами чаще стали появляться и слова славянского происхождения:

$\begin{array}{ll}\text { Halunke } & \text { чешск. cholomek } \\ \text { Jauche } & \text { польск.. jucha }\end{array}$




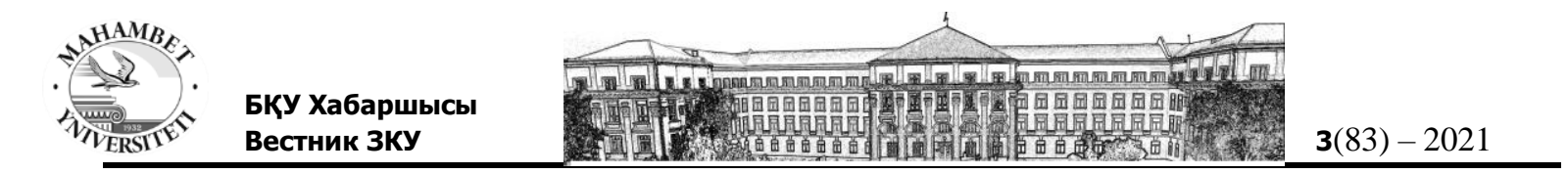

\section{Gurke чешск. okurka \\ Säbel польск. szabla}

Из арабского языка при посредничестве романских языков в немецкий словарь попадают Matratze, Karussell, Alkohol, Kaffee; а с американского континента в результате развития торговли - Mais, Kakao, Ananas, Orkan, Hängematte.

Суммируя основные моменты изложенного материала, можно в схематичном виде представить основные особенности формирования литературного немецкого национального языка в период от XII до XVIII столетий:

- Происходят изменения в системах склонения и спряжения. событий.

- Растущее использование настоящего времени (презенса) в описании прошлых словосложение.

- В словообразовании ранненововерхненемецкого большую роль играло

- Многие старые лексические единицы использовались в новых значениях.

- Вследствие экономических и общественных изменений стали активно формироваться специальные языки различных социальных групп, из которых многие слова и выражения проникли в национальный язык.

- Большое влияние оказывал латинский язык, значение других языков снизилось по сравнению с латинским.

- Наиболее значимым для развития национального немецкого языка оказался восточно-средненемецкий район Германии, в котором происходило своего рода смешение нижненемецких, средненемецких и верхненемецких элементов.

\section{ЛИТЕРАТУРА}

[1] Tichy E. Indogermanisches Grundwissen für Studierende sprachwissenschaftliches Diszipline. - Bremen: Hempen Verlag, 2000.

1962.

[2] Гухман М.М. Сравнительная грамматика германских языков / Гухман М.М. - М.,

[3] Schweikle, G. Germanisch-deutsche Sprachgeschichte im Überblick. - Stuttgart: Verlag J. B. Metzler, 2002. 2002.

[4] Meier-Brügger, M. Indogermanische Sprachwissenschaft. - Berlin: Walter de Gruyter,

[5] Masařik, Z. Historische Entwicklung des Deutschen. - Praha: Státní pedagogické nakladatelství, 1989.

[6] Kohnen, T. The influence of "Latinate" constructions in Early Modern English: Orality and literacy as complementary forces. In Language Contact in the History of English, D. Kastovsky and A. Mettinger (eds), 171-194. Frankfurt: Lang. 2001.

[7] Schmidt, W. Geschichte der deutschen Sprache. Ein Lehrbuch für das germanistische Studium. - Stuttgart: S. Hirzel Verlag, 2007.

[8] Crivat, B. Geschichte der deutschen Sprache. Eine Einführung. Craiova: Ed. Universitaria. 2012

[9] Březinova, J. Die Entwicklung der Flexion des Substantivs und des Verbs vom Indoeuropäischen bis zum Neuhochdeutschen. - Třebič, 2006.

[10] Linn, A. R. and McLelland, N. Standardization. Studies from the Germanic languages. Amsterdam. - John Benjamins. 2002.

[11] Kienle, R. Historische Laut- und Formenlehre des Deutschen; Tübingen: Max Niemeyer Verlag, 1960.

[12] Scaglione, A. The Emergence of National Languages. Ravenna. - Longo Editore. 1984. 
[1] Tichy, E. (2000) Indogermanisches Grundwissen für Studierende sprachwissenschaftliches Diszipline [Indogermanisches Grundwissen für Studierende sprachwissenschaftliches Diszipline] Bremen: Hempen Verlag [in Deutsch].

[2] Guhman M.M. (1962). Sravnitel'naja grammatika germanskih jazykov [Comparative grammar of the Germanic languages] Moscow [in Russian].

[3] Schweikle, G. (2002) Germanisch-deutsche Sprachgeschichte in a review [GermanicGerman language history at a glance] Stuttgart: J. B. Metzler [in Deutsch].

[4] Meier-Brügger, M. (2002). Indogermanische Sprachwissenschaft [Indo-European Linguistics]; Berlin: Walter de Gruyter [in Deutsch].

[5] Masařik, Z. (1989). Historische Entwicklung des Deutschen [Historical development of German] Praha: Státní pedagogické nakladatelství [in Deutsch].

[6] Kohnen, T. (2001). The influence of "Latinate" constructions in Early Modern English: Orality and literacy as complementary forces. In Language Contact in the History of English [] D. Kastovsky and A. Mettinger (eds), 171-194, Frankfurt: Lang. [in Deutsch].

[7] Schmidt, W. (2007). Geschichte der deutschen Sprache. Ein Lehrbuch für das germanistische Studium [History of the German language. A textbook for studying German] Stuttgart: S. Hirzel Verlag [in Deutsch].

[8] Crivat, B. (2012). Geschichte der deutschen Sprache. Eine Einführung [History of the German language. An introduction] Craiova: Ed. Universitaria [in Deutsch].

[9] Březinova, J. (2006). Die Entwicklung der Flexion des Substantivs und des Verbs vom Indoeuropäischen bis zum Neuhochdeutschen [The development of the inflection of the noun and the verb from Indo-European to New High German]. Třebič [in Deutsch].

[10] Linn, A. R. \& McLelland, N. (2002) Standardization. Studies from the Germanic languages. Amsterdam: John Benjamins [in Deutsch].

[11] Kienle, R. (1960). Historische Laut- und Formenlehre des Deutschen [Historical theory of sounds and forms in German]. Tübingen: Max Niemeyer Verlag [in Deutsch].

[12] Scaglione, A. (1984). The Emergence of National Languages. Ravenna: Longo Editore [in Deutsch].

\section{Поляничко М.В., Яковлюк А.Н. \\ ХІІ - ХVІІІ ҒАСЫРЛАР МЕН ОНЫН ЛЕКСИКАЛЫК ЖӘНЕ ГРАММАТИКАЛЫҚ ЕРЕКШЕЛІКТЕРІ КЕЗІНДЕ ҰЛТТЫҚ НЕМІС ТІЛІНІҢ ҚАЛЫПТАСУЫ}

Андатпа. Салыстырмалы тарихи зерттеу әдісі қазіргі грамматикалық жүйелердің қалыптасу процесін, тілдердің сөздік қорының қалыптасуын көрсетуге мүмкіндік береді.

Материалды талдау XII-XVIII ғасырлар кезеңінде әдеби неміс ұлттық тілінің қалыптасуының келесі негізгі ерекшеліктерін анықтады:

- Жіктеу және септеу жүйелерінде өзгерістер болып жатады қолданылуы.

- Өткен оқиғаларды сипаттауда осы шақтың (презенстің) өсіп келе жатқан

- Ерте жаңа жоғары неміс тілінің сөзжасамында сөз құрамы маңызды рөл атқарды.

- Көптеген ескі лексикалық бірліктер жаңа мағынада қолданылды.

- Экономикалық және әлеуметтік өзгерістердің нәтижесінде әр түрлі әлеуметтік топтардың арнайы тілдері белсенді түрде қалыптаса бастады, олардың көпшілігі ұлттық тілге еніп кетті.

- Латын тілі үлкен әсер етті, латын тілімен салыстырғанда басқа тілдердің маңызы төмендеді. 
- Ұлттық неміс тілінің дамуы үшін ең маңыздысы-Германияның Шығыс-Орта Герман аймағы болды, онда төменгі неміс, орта неміс және жоғары неміс элементтері араласып кетті.

Кілт сөздер: ұлттық неміс тілі, грамматикалық форма, сөздік құрам, композиттер, сөзжасам.

\section{Polyanichko Maria, Yakovluk Alexander \\ LEXICAL AND GRAMMATICAL PECULIARITIES OF THE FORMATION OF A NATIONAL GERMAN LANGUAGE IN THE PERIOD OF XII - XVIII CENTURIES}

Annotation: Comparative historical research method gives the opportunity to show the process of formation of modern grammatical systems, the formation of the vocabulary of languages. The analysis of the material revealed the following main features of the formation of the German national literary language in the period of XII - XVIII centuries:

- Changes in the systems of declension and conjugation.

- The growing use of real time (presence) in the description of past events. World-building played a significant role in the word formation of early high German language in compounding.

- Many older lexical items in new meanings.

- Due to the economic and social changes the special languages of different social groups began to shape actively, from which many words and expressions entered in the national language.

- Latin language had a great influence, the meaning of other languages decreased in comparison with Latin.

- Most significant for the development of a national German language was East-Central region of Germany, which was a kind of mixture of low German, Central and high German elements. formation.

Keywords: German national language, grammatical form, vocabulary, composites, word 